\title{
Fumigation Potential at Inland and Coastal Power Plant Sites
}

Prepared by C. G. Lindsey, J. V. Ramsdell

Pacific Northwest Laboratory

Operated by

Battelle Memorial Institute

Prepared for

U.S. Nuclear Regulatory

Commission 


\section{NOTICE}

This report was prepared as an account of work sponsored by an agency of the United States Government. Neither the United States Government nor any agency thereof, or any of their employees, makes any warranty, expressed or implied, or assumes any legal liability of responsibility for any third party's use, or the results of such use, of any information, apparatus, product or process disclosed in this report, or represents that its use by such third party would not infringe privately owned rights.

\section{Availability of Reference Materials Cited in NRC Publications}

Most documents cited in NRC publications will be available from one of the following sources:

1. The NAC Public Document Room, 1717 H Street, N.W. Washington, DC 20555

2. The NRC/GPO Sales Program, U.S. Nuclear Regulatory Commission, Washington, DC 20555

3. The National Technical Information Service, Springfield, VA 22161

Although the listing that follows represents the majority of documents cited in NRC publications, it is not intended to be exhaustive.

Referenced documents available for inspection and copying for a fee from the NAC Public Document Room include NRC correspondence and ir.ternal NRC memoranda; NRC Office of Inspection and Enforcement bulletins, circulars, information notices, inspection and investigation notices; Licensee Event Reports; vendor reports and correspondence; Commission papers; and applicant and licensee documents and correspondence.

The following documents in the NUREG series are available for purchase from the NRC/GPO Sales Program: formal NRC staff and contractor reports, NRC-sponsored conference proceedings, and NRC booklets and brochures. Also available are Regulatory Guides, NRC regulations in the Code of Federal Regulations, and Nuclear Regulatory Commission /ssuances.

Documents available from the National Technical Information Service include NUREG series reports and technical reports prepared by other federal agencies and reports prepared by the Atomic Energy Commission, forerunner agency to the Nuclear Regulatory Commission.

Documents available from public and special technical libraries include all open literature items, such as books, journal and periodical articles, and transactions. Federal Register notices, federal and state legislation, and congressional reports can usualiy be obtained from these libraries.

Documents such as theses, dissertations, foreign reports and transiations, and non-NRC conference proceedings are available for purchase from the organization sponsoring the publication cited.

Single copies of NAC draft reports are available free upon written request to the Division of Technical Information and Document Control, U.S. Nuclear Regulatory Commission, Washington, DC 20555.

Copies of industry codes and standards used in a substantive manner in the NRC regulatory process are maintained at the NRC Library, 7920 Norfolk Avenue, Bethesda, Maryland, and are available there for reference use by the public. Codes and standards are usually copyrighted and may be purchased from the originating organization or, if they are American National Standards, from the American National Standards Institute, 1430 Broadway, New York, NY 10018. 
NUREG/CR-3352

PNL-4760

\section{Fumigation Potential at Inland and Coastal Power Plant Sites}

Manuscript Completed: July 1983

Date Published: October 1983

Prepared by

C. G. Lindsey, J. V. Ramsdell

Pacific Northwest Laboratory

Richland, WA 99352

\section{Prepared for}

Division of Systems Integration

Office of Nuclear Reactor Regulation

U.S. Nuclear Regulatory Commissiọn

Washington, D.C. 20555

NRC FIN B2514 

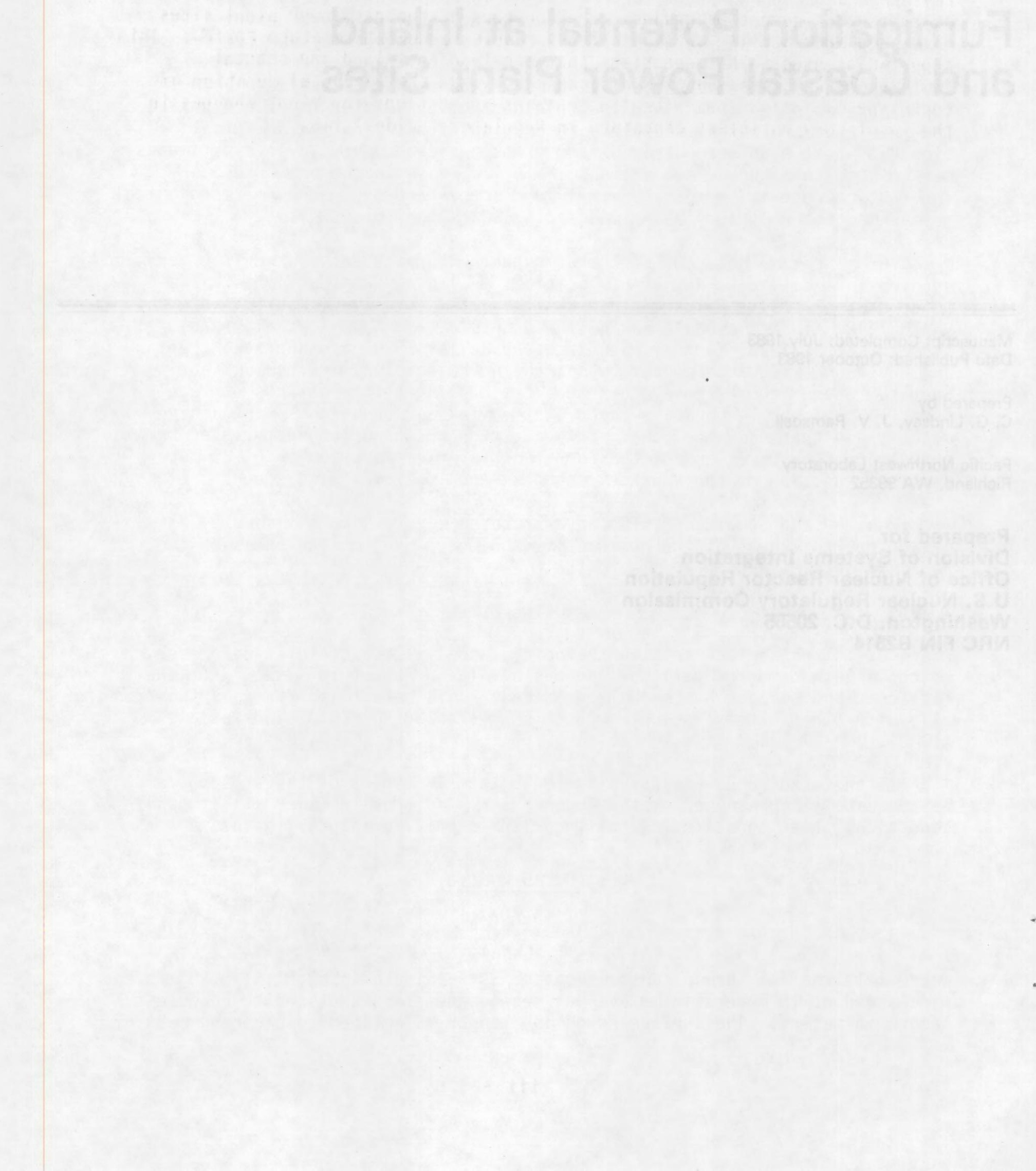


\section{ABSTRACT}

The literature on fumigation at inland and coastal sites has been reviewed, and the NRC Regulatory Positions on the treatment of $f$ unigation in assessment of potential accident consequences at nuclear power plant sites have been examined in the light of the results of the literature review. This report discusses: the mechanisms that can lead to inland and coastal fumigation, their frequencies of occurrence, and the potential duration of each type of fumigation. It also contains suggestions for minor changes in the Regulatory Positions contained in Regulatory Guide 1.145. 


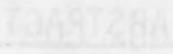

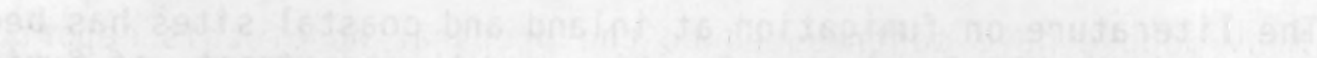

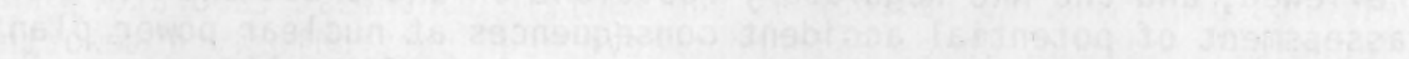

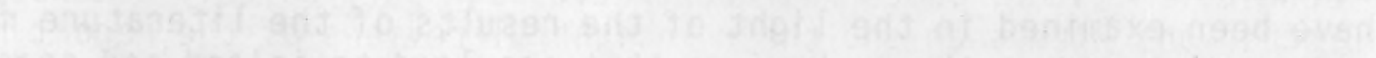

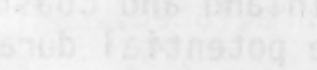

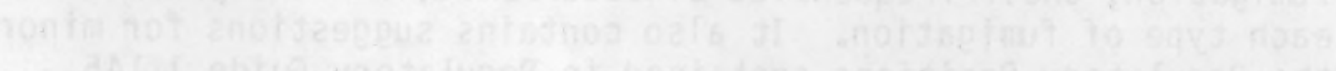

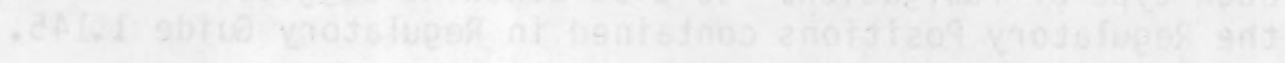




\section{ACKNOWLEDGMENTS}

Many people have contributed to the preparation of this report. The efforts of Dr. R. K. Hadlock at the Pacific Northwest Laboratory and the NRC Technical Monitor, James Fairobent have been particularly noteworthy. Discussions with them and their insightful reviews of the report have been extremely helpful. Their assistance is greatly appreciated. 



\section{CONTENTS}

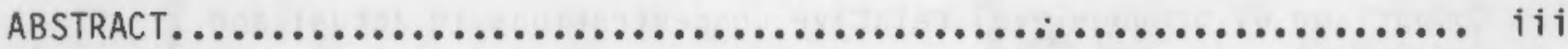

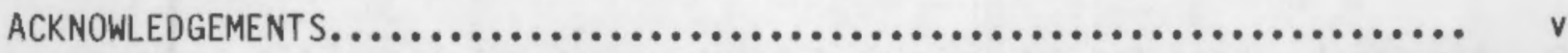

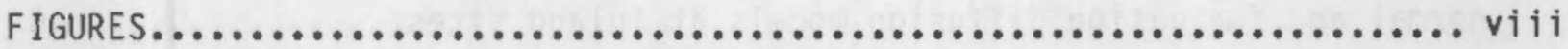

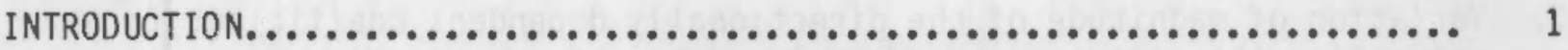

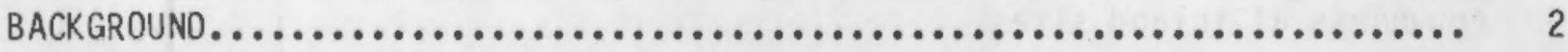

FUMigation AT InLANO SITES...................................... 7

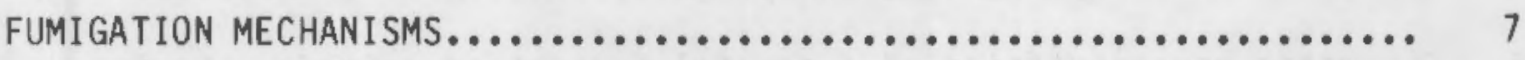

FORECASTING FUMIGATION................................... 9

EPISOOE OURATION.......................................... 14

FUMIGATION AT COASTAL SITES $. \ldots \ldots \ldots \ldots \ldots \ldots \ldots \ldots \ldots \ldots \ldots \ldots \ldots \ldots, 16$

THE INTERNAL BOUNDARY LAYER $\ldots \ldots \ldots \ldots \ldots \ldots \ldots \ldots \ldots \ldots \ldots \ldots \ldots \ldots$

OURATION...................................................... 18

ESTIMATING COASTAL FUMIGATION CONCENTRATIONS $. . \ldots \ldots \ldots \ldots \ldots \ldots \ldots . . .19$

FUMIGATION CRITERIA FOR REGULATORY GUIDE $1.145 \ldots \ldots \ldots \ldots \ldots \ldots \ldots \ldots \ldots, 21$

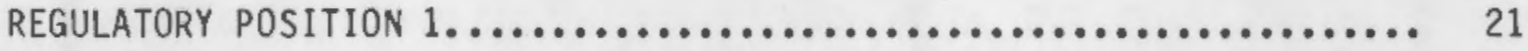

REGULATORY POSITION $2 . \ldots \ldots \ldots \ldots \ldots \ldots \ldots \ldots \ldots \ldots \ldots \ldots \ldots \ldots \ldots, 21$

In 1 and Si tes............................................... 22

Coastal Sites........................................... 22

APPLICATION TO EMERGENCY RESPONSE $\ldots \ldots \ldots \ldots \ldots \ldots \ldots \ldots \ldots \ldots \ldots \ldots, 23$

REFERENCES.................................................... 24 


\section{FIGURES}

1. Comparison of ground-level relative concentrations in actual and model fumigation episodes.................................... 3

2. A general scheme for determining fumigation potential and choosing the normal and fumigation diffusion models at inland sites............. 6

3. Variation of magnitude of the directionally dependent coefficient for estimating the nocturnal boundary layer height on upwind surface roughness at inland sites.....................................

4. Growth of diffusion coefficients at one and ten kilometers during the course of an inland fumigation episode..........................

5. Schematic representation of a coastal fumigation episode, showing important distances............................................

6. Typical internal boundary layer thickness as a function of distance from a coastline assuming "E" and "F" over-water stability.......... 


\section{INTRODUCTION}

Fumigation occurs when a plume, initially embedded in an elevated relatively non-turbulent layer of the atmosphere, encounters a turbulent mixing layer. The term fumigation was originally introduced by Hewson and Gill (1944) in reference to air pollution near Trail, British Columbia. The fumigation process is of interest to the U.S. Nuclear Regulatory Commission (NRC) because it can lead to ground-level concentrations, when and where the plume comes to the ground, that are higher than the concentrations before or after the fumigation episode.

Fumigation is discussed in texts on atmospheric diffusion (e.g. Slade 1968, Csanady 1973, Pasquill 1974, and Hanna, Briggs and Hosker 1982). In general, these discussions describe the fumigation phenomenon qualitatively and provide basic equations for use in estimating concentrations during funigation episodes.

The U. S. Nuclear Regulatory Commission provides guidance on the treatment of fumigation to licensees and applicants through Regulatory Guide 1.145 (USNRC 1983). In this guide, the NRC outlines a simple deterministic procedure that follows from the standard textbook approach. The procedure is thought to be highly conservative (i.e., overestimates concentrations) when applied to estimation of long-term concentrations. The conservatism results from two factors: the failure to consider the frequency and duration of the conditions responsible for fumigation, and the failure to consider the correlation between fumigation conditions and the wind directions.

The objectives of this report are to present a compilation and synthesis of the recent developments related to fumigation modeling and to suggest possible revisions to the NRC guidance on the treatment of fumigation. Specifically, it discusses the mechanisms that are responsible for fumigation at inland and coastal sites, it discusses the frequency and duration of fumigation for the two types of sites, and it describes schemes for forecasting and identifying potential fumigation conditions using meteorological data that are likely to be available at nuclear facilities or readily obtainable from public information sources such as the National Weather Service. Finally, potential alternatives to the current NRC guidance are offered. 


\section{BACKGROUND}

Fumigation is an atmospheric transition process. The onset of a fumigation episode occurs when a plume in a stable layer aloft comes into contact with a relatively unstable turbulent lower layer. The contact may be the result of an increase in thickness of the lower layer with time such as accompanies the warming of the ground during the day, or it may be the result of an increase in thickness of the lower layer in space along the path of the plume as occurs near coasts. At the point or time of the encounter between the plume and the lower layer, material in the pl ume begins to mix downward to the ground. If the time required for the mixing to occur is small compared with the time required for the effluent to travel from the source to the receptor, the concentrations at the receptor during the transition may be higher than the steady state concentrations either before or after the transition.

When fumigation results from a temporal increase in the thickness of the turbulent boundary layer, the duration of the episode depends upon the distance from the source. Near the source, the episode will be short-lived because the time required for material to travel the distance between the source and receptor is short. Material initially released into the unstable layer is not subject to fumigation, although it may be trapped below the elevated stable layer, which would limit the extent of vertical mixing in the plume. The greater the distance between the source and the receptor, the longer it will take for the last of the material initially released into the stable layer to reach the receptor.

When fumigation results from a spatial change in the height of the boundary between the layers, the duration of the fumigation episode has two definitions. The first definition is related to duration of an episode at a specific location on the ground, and the other is related to the duration of the conditions tht result in fumigation potential. The distinction between the cases is that in the first case, not only are the precursor conditions for fumigation required, but the wind direction must also remain essentially constant. Hence, the duration of fumigation at a specific location will likely be of shorter duration than the existence of the fumigation conditions. In no case can the duration of fumigation at a point exceed the duration of the precursor conditions.

Qualitatively, the effluent concentration at a ground-level receptor might appear to follow the solid line in Figure 1 as a function of time during a fumigation episode. Material is initially released into an elevated stable layer. At time to the top of the boundary layer reaches the bottom of the plume and the material begins a rapid mixing process. This marks the onset of the fumigation episode. A short time later, at time $t_{1}$, the concentration at . ground-level reaches a maximum. The period between $t_{0}$ and $t_{1}$ is the time that it takes the material in the plume to become uniformly mixed within the lower unstable layer. After reaching a maximum, the concentration decreases until, at time $t_{2}$, it approaches a value that is representative of the turbulence in the unstable surface layer. The decrease in the concentration between $t_{1}$ and 
$t_{2}$ is associated with increasing horizontal diffusion and a continued increase in the height of the boundary between the layers. The duration of the funigation episode is $t_{2}-t_{0}$.

The fumigation process, as depicted by the solid line in Figure 1 , is difficult to represent in the Gaussian plume models that are generally used to evaluate the potential consequences of releases from nuclear power plants. A common alternative has been to treat the process as a sequence of three separate steady state conditions. Prior to the onset of fumigation the ground-level concentration is assumed to be zero or to be described by the normal elevated plume diffusion equation. During the fumigation episode, the concentration is assumed to be constant at a maximum level, which is primarily associated with the release conditions. After a suitable time, diffusion is again assumed to be in a steady state condition that is a function of the existing atmospheric conditions. This approximation is shown in figure 1 by the dashed line.

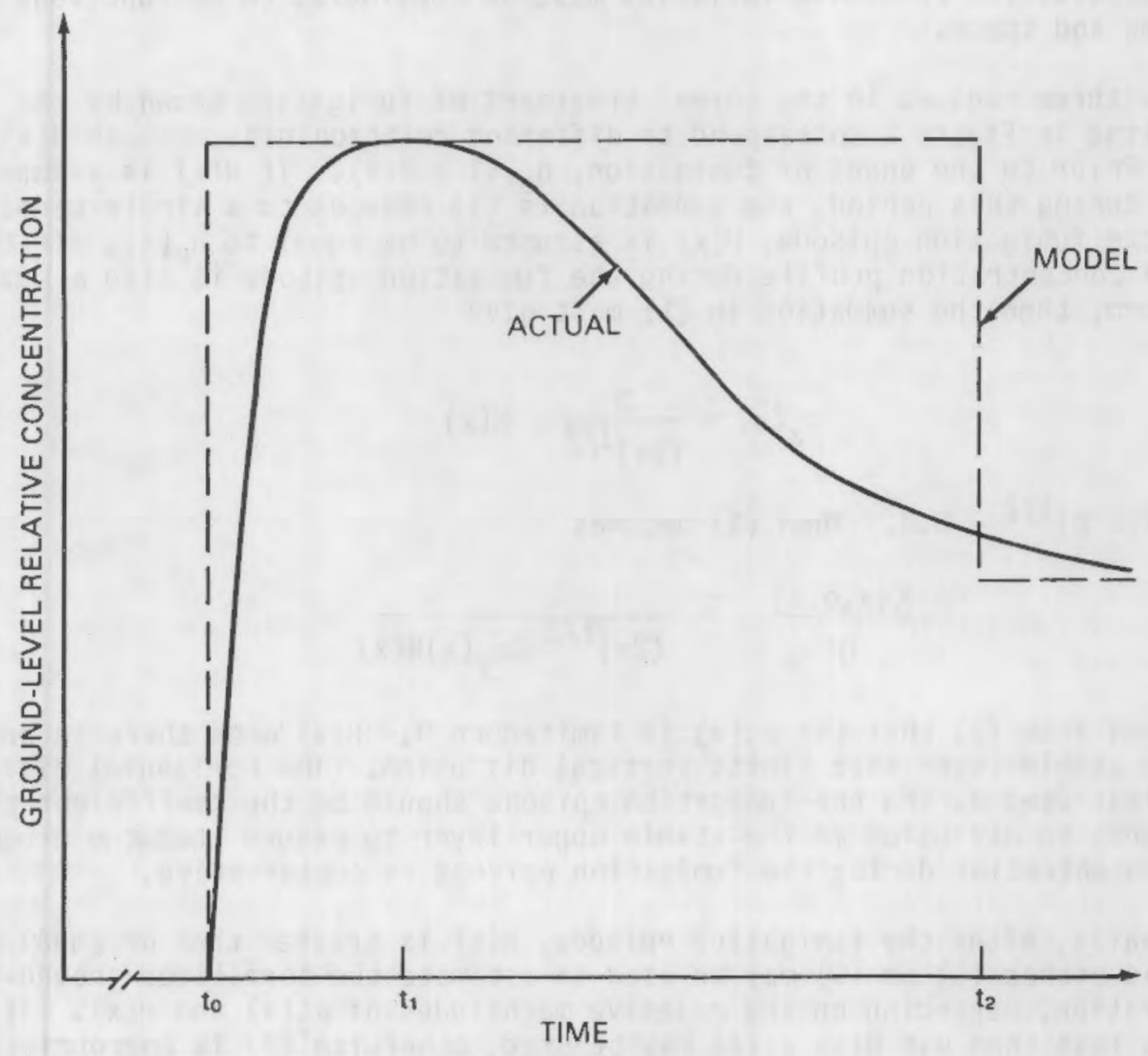

FIGURE 1. Comparison of Ground-Level Relative Concentrations in Actual and Model Fumigation Episodes. 
Moving toward a more quantitative definition of the concentration during fumigation, the Gaussian model for the ground-level air concentration in a plume from an elevated point source where both the earth's surface and the top of the atmospheric mixing layer are assumed to reflect material can be used for illustration. That model is:

$$
\frac{x(x, 0,0)}{Q^{\prime}}=\frac{1}{\pi U \sigma_{y}(x) \sigma_{z}(x)} \sum_{n=-\infty}^{\infty} \exp \left\{-\frac{1}{2}\left[\frac{2 n H(x)-h_{e}(x)}{\sigma_{z}(x)}\right]^{2}\right\}
$$

where $\chi(x, 0,0)$ is the concentration at ground-level under the center of the plume at a distance $x$ from the source, $Q^{\prime}$ is the rate at which material is released, $U$ is the wind speed at release height, $\sigma_{y}(x)$ and $\sigma_{z}(x)$ are the horizontal and vertical diffusion coefficients, respectively, $H(x)$ is the height of the top of the mixing layer, and $h_{e}(x)$ is the effective release height of the plume (Csanady 1973). The release rate and wind speed can be assumed to be functions only of time without significant impact on the result, but in general the remaining variables must be considered to be functions of both time and space.

The three regions in the normal treatment of fumigation shown by the dashed line in Figure 1 correspond to different relationships between $H(x)$ and $h_{e}(x)$. Prior to the onset of fumigation, $h_{e}(x)>H(x)$. If $H(x)$ is assumed to be zero during this period, the summation in (1) reduces to a single term. During the fumigation episode, $H(x)$ is assumed to be equal to $h_{e}(x)$. If the vertical concentration profile during the fumigation episode is al so assumed to be uniform, then the summation in (1) must give

$$
\sigma_{z}(x)=\frac{2}{(2 \pi)^{1 / 2}} \quad H(x)
$$

where $2 /(2 \pi)^{1 / 2}=0.8$. Then (1) becomes

$$
\frac{x(x, 0,0)}{Q^{\prime}}=\frac{1}{(2 \pi)^{1 / 2} U \sigma_{y}(x) H(x)} .
$$

It follows from (2) that the $\sigma_{7}(x)$ is limited to $0.8 H(x)$ when there is an elevated stable layer that limits vertical diffusion. The horizontal diffusion coefficient used during the fumigation episode should be the coefficient that corresponds to diffusion in the stable upper layer to ensure that the groundlevel concentration during the fumigation episode is conservative.

Finally, after the fumigation episode, $H(x)$ is greater than or equal to $h_{e}(x)$ and either (1) or (3) may be used to est imate the normalized ground-level concentration, depending on the relative magnitudes of $\sigma_{z}(x)$ and $H(x)$. If $\sigma_{z}(x)$ is less than $0.8 \mathrm{H}(\mathrm{x})$, (1) may be used, otherwise ${ }^{2}(3)$ is appropriate. After the fumigation episode, the $\sigma_{y}(x)$ used should correspond to diffusion in the turbulent surface layer because the effluent was initially released in the unstable lower layer of the atmosphere. 
A figure similar to Figure 1 could be drawn for fumigation resulting from the intersection of an elevated plume with an inclined boundary between the turbulent mixing layer and an upper stable layer by making the abscissa a function of distance rather than time. In this case, the decrease in groundlevel concentration following the maximum could be attributed to changing azimuth of the plume as well as to increasing thickness of the turbulent boundary layer.

A general scheme for detemining the appropriate diffusion model at a given time on the basis of past and current meteorological conditions is shown in Figure 2. A fumigation potential flag is used to keep track of the meteorological conditions from one observation period to the next. If the flag is on, the precursor conditions to fumigation have been met, and the plume will either remain aloft or fumigation will begin during the current time period. If the fumigation potential flag is off, diffusion during the current time interval will be normal with the effluent being either in the mixing layer or above it. Determination of which of the two alternative conditions exists is based on the surface-level atmospheric stability and the est imated turbulence conditions at plume height.

Diffusion estimates for nuclear power plants made with current Nuclear Regulatory Commission models, i.e., XOQDOQ (Sagendorf, Goll and Sandusky 1982), and PAVAN (Bander 1982) make use of winds that are specified as functions of time and effective release height and diffusion coefficients that are functions of both time and distance. Thus, the only additional information required to use the scheme to estimate fumigation conditions at inland locations is a method for estimating the turbulence conditions at plume height or, equivalently, the thickness of the surface mixing layer. Use of the scheme to estimate funigation conditions at coastal sites will require more detailed estimates of the spatial variation of the diffusion coefficients and the estimation of the temporal and spatial variation of the mixing layer thickness.

The next section considers fumigation at inland sites, or more specifically, sites characterized by relatively simple terrain where spatial variations in the characteristics of the atmosphere can be ignored in relation to the temporal variations. It is followed by a section that considers fumigation at coastal sites where both spatial and temporal variations of the atmosphere are important factors. It is assumed that the dominant topographic feature is the change in surface conditions that is associated with the coastline. The last section of the report contains alternative methods for treating fumigation that might be included in Regulatory Guide 1.145 (USNRC 1983). 


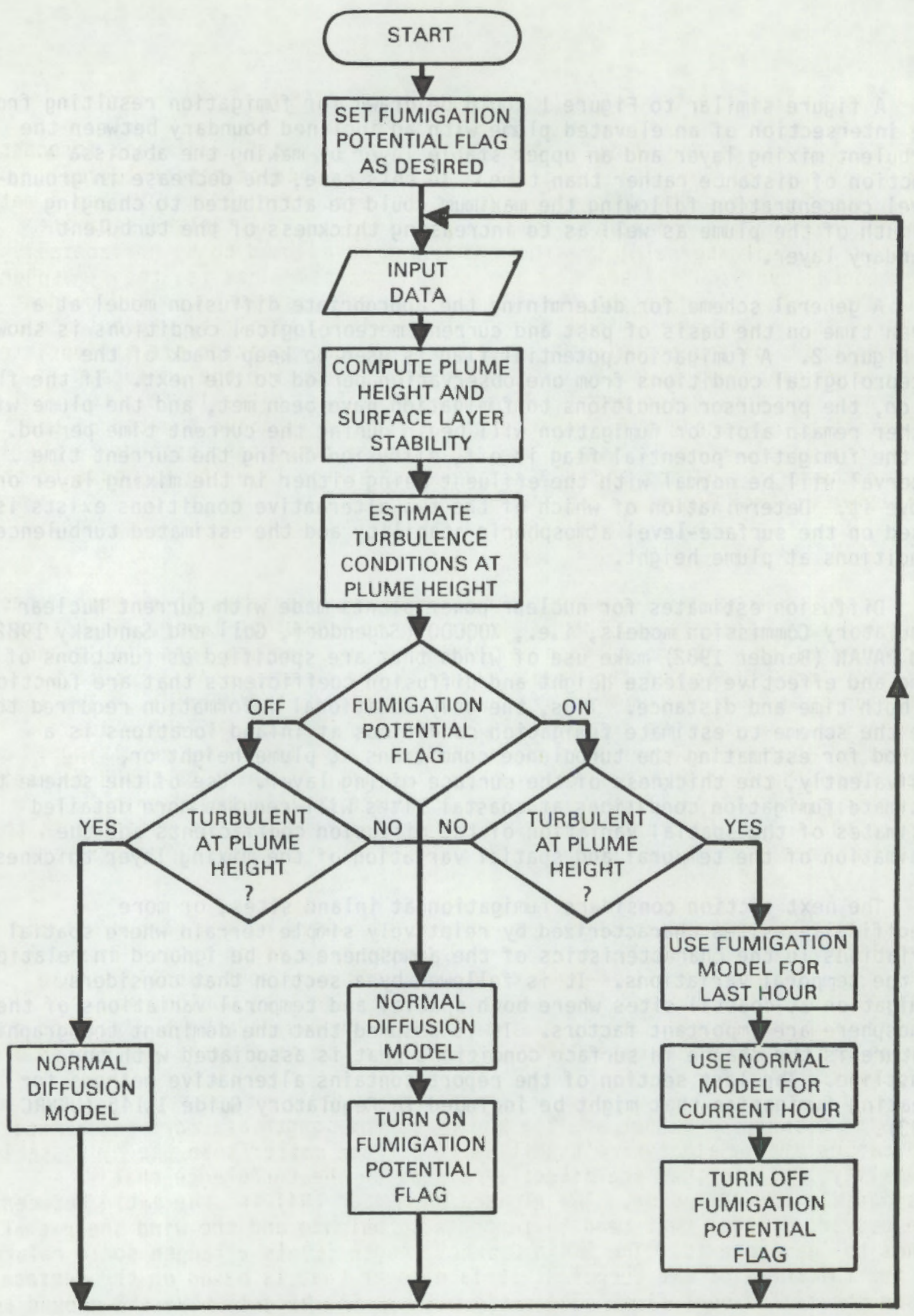

FIGURE 2. A General Scheme For Determining Fumigation Potential and Choosing Choosing the Normal and Fumigation Diffusion Models at Inland Sites. 


\section{FUMIGATION AT INLAND SITES}

Evaluation of the fumigation potential for a specific site and forecasting the likelihood of fumigation under a specific sequence of meteorological conditions requires the identification of the precursor conditions and a method for determining the potential onset of an episode. At an inland site in relatively simple terrain, the atmosphere can be assumed to be horizontally homogeneous over spatial scales of a few kilometers. That is, the atmospheric conditions.at a fixed height above the ground are assumed to be independent of the horizontal position. Thus, estimates of winds, stability, turbulence and the thickness of the turbulent mixing layer for one position are appropriate for use at other nearby positions. With this assumption, the precursor condition for fumigation near power plants at inland sites is that the effective release height for power plant effluents is above the top of the turbulent layer. Similarly, the only way that a fumigation episode can begin is for the height of the top of the turbulent mixing layer to increase to the effective release height.

\section{FUMIGATION MECHANISMS}

Within the basic assumption of horizontal homogeneity, three mechanisms can lead to an increase in the thickness of the turbulent layer. The first is surface heating. As the surface air is warmed, it becomes less stable and buoyancy forces that tend to damp turbulence are reduced. As a result, friction-induced turbulence is propogated farther in the vertical. The second mechanism is an increase in surface level winds. As the surface winds increase, the kinetic energy in the turbulence will increase, resulting in a gradual increase in the thickness of the turbulent layer. The third mechanism is an increase in upper level wind speeds during stable atmospheric conditions. In this case, if the wind speed gradient becomes sufficient, the flow may become unstable resulting in shear-induced turbulence despite the stability of the atmosphere.

Throughout this discussion atmospheric stability refers to hydrostatic stability as determined by the potential temperature lapse rate. Increasing potential temperature with height corresponds to a hydrostatically stable situation in which buoyancy forces tend to damp vertical motions and turbulence. Various stability classification schemes have been developed for use in estimating atmospheric diffusion. Their use is primarily a matter of convenience.

The Richardson Number and the Monin-0bukhov length are more fundamental indicators of the atmosphere's ability to diffuse matter than the hydrostatic stability, because they are directly related to the turbulence that is responsible for diffusion. The Richardson Number ( $R i$ ) is the ratio between the buoyancy forces that tend to suppress turbulence and the wind shear that tends to generate $i t$. The Monin-Obukhov length ( $L$ ) is a length scale related to the thickness of the turbulent surface layer that is based on the surface shear stress and heat flux. The ratio between the height above the ground and the Monin-0bukhov length $(z / L)$ is an indicator of the ability of the atmosphere to sustain turbulence. $R i$ and $z / L$, which are discussed in diffusion and 
boundary layer meteorology texts (e.g. Haugen 1973, Hanna, Briggs and Hosker 1982), are both positive when the atmospheric hydrostatic stability tends to suppress turbulence and negative when it enhances turbulence. Further, mathematical relationships have been developed between the $\mathrm{Ri}$ and $\mathrm{z} / \mathrm{L}$.

Either of these two dimensionless numbers could be used in the evaluation of fumigation potential and onset, however, $\mathrm{Ri}$ is easier to compute from readily available data. There are several forms of the Richardson Number. The gradient Richardson Number is defined as

$$
R i=\frac{g}{T} \frac{\partial \theta / \partial z}{(\partial U / \partial z)^{2}}
$$

where $g$ is the gravitational constant, $T$ is the ambient air temperature in ${ }^{0} \mathrm{~K}$, $\partial \theta / \theta z$ is the potential temperature gradient and $\partial U / \partial z$ is the wind shear.

As the hydrostatic forces in the atmosphere that suppress turbulence become larger, the Richardson Number becomes more positive. Ultimately, a limiting value is reached where the hydrostatic forces effectively bring the turbulence to a halt. This 1 imiting $\mathrm{Ri}$ appears to be somewhat larger than 0.20 (Businger 1973). The existence of a limit is important because it makes it possible to use the Richardson Number to indicate the low turbulence levels associated with elevated stable layers and potential fumigation conditions. The Richardson Number is implicitly a function of height. The height dependence of $z / L$ is explicit.

Each of the mechanisms associated with the onset of fumigation episodes can be related to changes in the Richardson Number. Heating the lower portion of the atmosphere reduces the potential temperature gradient, thereby reducing the Richardson Number. This process starts at the surface and works its way toward the top of the mixing layer. Ultimately, the increase in the lowerlevel temperatures causes the Richardson Number at the top of the mixing layer to fall below the critical value and the mixing layer thickness increases. Similarly, an increase in wind speed within the mixing layer will cause the potential temperature gradient to approach zero, which will reduce the forces that suppress turbulence.

If the potential temperature gradient is large and turbulence is minimal, the upper-level winds can become decoupled from the lower winds and the retarding effects of surface friction. When decoupling occurs, the upper winds are free to accelerate to the geostrophic or gradient speed. At the same time, the lower-level winds lose a source of energy that has been helping to sustain them. The net result of decoupling is an increase in wind shear across the boundary between the layers. This increase may be large enough to drive the Richardson Number bel ow the critical value, thus increasing the level of turbulence. The turbulence eventually reduces the wind shear, which results in an increase in $\mathrm{Ri}$ and reduced turbulence. 
The turbulence conditions between the effective plume release height and the ground-level determine if the atmospheric conditions at any specific time could lead to a fumigation episode. If the effective release height is sufficiently low, the wind measurements made at the upper levels of a tower can be used to evaluate turbulence at plume height. Similarly, a remote sensing device, such as a Doppler acoustic sounder can be used to evaluate both the turbulence at plume height and the thickness of the mixing layer. Finally, the low-level meteorological measurements coupled with several mathematical relationships that have been derived from atmospheric boundary layer experiments can be used to make the evaluation. This last case is the ane of primary interest because it is most generally applicable and the needed meteorological measurements are already being made at nuclear power plant sites.

The nighttime behavior of the atmosphere near the earth's surface has been studied in detail at a number of locations including Wangara in Australia (Clarke et al. 1971, Melgarejo and Deardorff 1974, Yu 1978, Mahrt, Andre and Heald 1982) and Minnesota (Readings et al. 1974, and Ka imal et al . 1976), Kansas (Kaimal 1973, Caughey, Wyngaard and Kaimal 1979) and Nebraska (Lettau and Davidson 1957, and Caughey, Wyngaard and Kaimal 1979) in the United States. These studies have shown that the cooling of the earth's surface establishes a stable boundary layer that may extend to heights approaching 400 meters, and that only the lower portion of the nocturnal boundary layer remains turbulent. The thickness of the turbulent layer varied from 5 to 120 meters, and is a function of the surface roughness and low-level wind speed.

Benkley and Schulman (1979) have proposed a very simple method of estimating the thickness of the nocturnal turbulence layer on the basis of the Nebraska data. That relationship is:

$$
H=0.185 U_{\star} / f
$$

where $U_{*}$ is the surface friction velocity, and $f$ is the Coriglis parameter, which is a function of latitude and has a value of about $10^{-4} \mathrm{sec}^{-1}$ for the latitude band covered by the United States. This relationship agrees functionally with other models including those suggested by $\mathrm{Yu}_{\mathrm{u}}$ (1978) and Wetzel (1982).

If the wind speed variation in the bottom 10 meters of the atmsophere can be adequately represented by the logarithmic wind profile under all atmospheric conditions, then substituting the logarithmic profile into (5) gives

$$
H=\frac{0.185 k U(10)}{f \ln \left(10 / z_{0}\right)}
$$

where $k$ is the Von Karman constant which has a value of about $0.4, U(10)$ is the wind speed at 10 meters in meters per second and $z_{0}$ is the surface roughness length in meters. The surface roughness length is related to the roughness of 
the ground near the wind measurement location and can be determined from wind measurements on cloudy days during high wind speeds. It may be a function of wind direction, but in other respects it should be constant. Values of $z_{0}$ for typical nuclear power plant sites should range between 0.01 and 1 meters. Counihan (1975) presents an extended discussion that can be used to estimate $z_{0}$ directly from site characteristics. His conclusions are summarized in the following table:

\begin{tabular}{lll} 
Terrain Type & \multicolumn{1}{c}{ Examples } & Roughness Length $\left(z_{0} m\right)$ \\
\hline Smooth & Sea, Ice, Mud & $10^{-5}$ to $2 \times 10^{-3}$ \\
Mod. Rough & Grass, Crops & $10^{-3}$ to 0.2 \\
Rough & Rural, Suburbs & 0.2 to 1.5 \\
Very Rough & Urban & 1.5 to 4.0
\end{tabular}

Of the factors in (6) only $z_{0}$ and the wind speed are variables, therefore (6) can be rewritten as

$$
H=C(\theta) U(10)
$$

where $C(\theta)$ is a function only of wind direction, and contains the effects of the variation of upwind surface on $z_{0}$. Thus, using the Benkley and Schulman model, the thickness of the nocturnal turbulent mixing layer at a site can be estimated from wind speed and direction observations. Figure 3 shows the variation of $C(\theta)$ with $z_{0}$ for a 10 meter wind measurement height using the constant 0.185 given by Benkley and Schulman.

Benkley and Schulman indicate that the mixing layer thicknesses computed from (7) may be somewhat too large. Therefore, it may be appropriate to reduce the thickness est imated from (7) as a conservative measure to increase the frequency of fumigation conditions. Benkley and Schulman suggest that a reduction of the estimated thickness by about one third gives thicknesses that agree with observed values on the average.

A climatological frequency of mixing layer thicknesses during stable atmospheric conditions provides part of the information needed to estimate the frequency of fumigation precursor conditions at a site. The remaining information is the effective release height for the plume under each combination of wind speed and stability. The frequency of occurrence of fumigation precursor conditions is the sum of the frequencies of those classes of combinations of wind speed, direction and stability for which the effective release height exceeds the turbulent mixing layer height. The average number of fumigation episodes annually can be estimated by converting the frequency of occurrence of fumigation precursor conditions to hours and dividing the result by the average duration that precursor conditions exist prior to fumigation.

Hanna (1969) and Mahrt (1981) have suggested models for the turbulent mixing layer thickness based on a bulk Richardson Number that uses the temperature difference across the boundary layer and the wind speed at the top of the boundary layer. This information is not likely to be available at nuclear power plants. However, if meteorological data are available from two levels on a tower that are both within the nocturnal boundary layer, it may be 


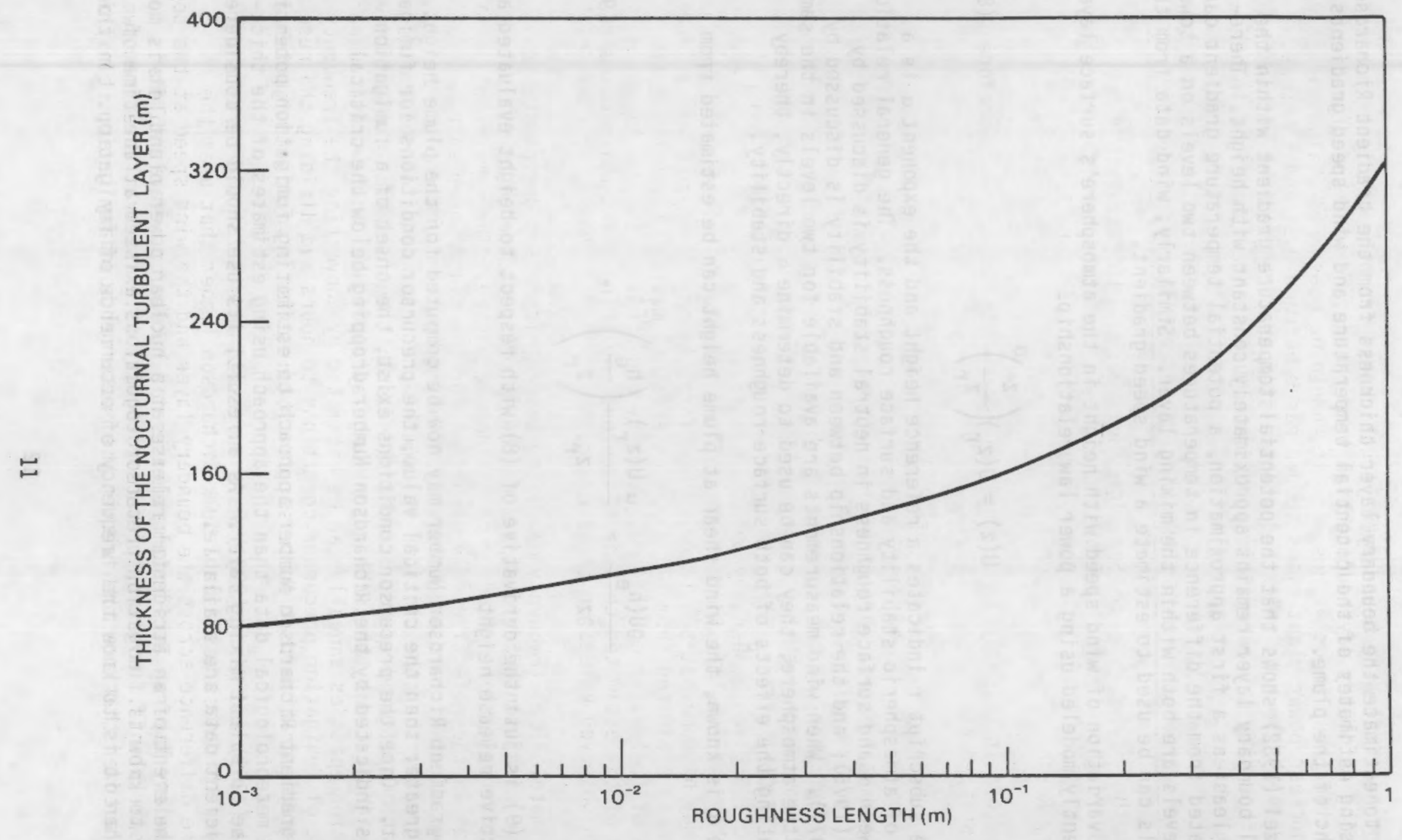

FIGURE 3. Variation of Magnitude of the Directionally Dependent Coefficient for Estimating the Nocturnal Boundary Layer Height on Upwind Surface Roughness at Inland Sites 
possible to estimate the boundary layer thickness from the gradient Richardson Number using estimates of the potential temperature and wind speed gradients at the height of the plume.

Wetzel (1982) shows that the potential temperature gradient within the nocturnal boundary layer remains approximately constant with height. Therefore, at least as a first approximation, a potential temperature gradient can be estimated from the difference in temperatures between two levels on a tower if the levels are both within the mixing layer. Similarly, wind data from the two levels can be used to estimate a wind speed gradient.

The variation of wind speed with height in the atmosphere's surface layer is frequently modeled using a power law relationship:

$$
U(z)=U\left(z_{r}\right)\left(\frac{z}{z_{r}}\right)^{\alpha}
$$

where the subscript $r$ indicates a reference height and the exponent $\alpha$ is a function of atmospheric stability and surface roughness. The general relationship between $\alpha$ and surface roughness in neutral stability is discussed by Counihan (1975); and the relationship between and stability is discussed by Touma (1977). When wind measurements are available for two levels in the same 1 ayer of the atmosphere, they can be used to determine $\alpha$ directly, thereby incorporating the effects of both surface roughness and stability.

Once $\alpha$ is known, the wind shear at plume height can be estimated from

$$
\frac{\partial U\left(h_{e}\right)}{\partial z}=\frac{\alpha U\left(z_{r}\right)}{z_{r}}\left(\frac{h_{e}}{z_{r}}\right)^{\alpha-1} \text {. }
$$

Equation (9) is just the derivative of (8) with respect to height evaluated at the effective release height.

The gradient Richardson Number may now be computed for the plume height. If it is greater than the critical value, the precursor conditions for fumigation exist. Once the precursor conditions exist, the onset of a funigation episode is indicated by the Richardson Number dropping bel ow the critical value.

The gradient Richardson Number approach to estimating fumigation potential uses more meteorological data than the approach using estimates of the thickness of the turbulent mixing layer. As a result, its use should be considered when sufficient data are available.

In the event of an accidental release at a nuclear power plant, it is more important to know if fumigation precursor conditions existed at the $t$ ime of release than it is to know the frequency of occurrence of fumigation. In this 
event, the aspects of funigation that are important include: the time of its onset, the position of the fumigation, its duration and the ground-level concentrations. Only the first three items are of concern here.

Clear skies and low wind speeds, which favor fumigation, are associated with high pressure systems. Under these conditions, the nocturnal temperature inversion becomes strongest, which facilitates the development of the fumigation precursor conditions. Surface heating during the morning hours is accompanied by rapid growth of the turbulent mixing layer and fumigation. Routine forecasts of the National Weather Service can provide useful information related to fumigation potential. Predicting the time of fumigation in advance requires an estimate of the rate at which the boundary layer will grow following sunrise.

Methods for predicting the thickness of the growth of the daytime boundary layer have been developed. For example, Benkley and Schulman (1979) describe a graphical procedure for estimating the thickness of the daytime mixing layer that uses temperatures at the surface and at the $700 \mathrm{mb}$ pressure level.

Figure 2 outlines a simple yet realistic procedure that provides continous information on fumigation conditions for use in the event of an emergency. It can also be used with climatological records to detemine the frequency of fumigation. The procedure is initiated by assuning that fumigation precursor conditions exist or don't exist. The assumption may be based on existing meteorological conditions, but it is not particularly critical because it only affects the procedure during the first time interval. The assumption is entered in the procedure by setting the status of the fumigation potential flag shown at the top of Figure 2. If the flag is set to on, the precursor conditions for fumigation are assumed to exist. While if it is set to off, they are assumed not to exist.

As meteorological data become available, the surface layer hydrostatic stability and an effective plume release height are est imated using the guidelines in Regulatory Guides 1.23 and 1.111. Then an indicator of turbulence at the effective release height is computed. The indicator may be either the Richardson Number or an estimate of the mixing layer thickness. This indicator and the fumigation potential flag are used to determine the current fumigation status and select the proper diffusion model for use during the current period.

Three atmospheric conditions are possible: nomal diffusion without fumigation, precursor conditions for fumigation exist, and fumigation is occuring or has occurred since the previous meteorological observation.

When the fumigation potential $\mathrm{flag}$ is on and the current meteorological data indicate that there isn't a likelihood of turbulence at plume height, fumigation probably did not occur during the previous period. If it is likely that there is turbulence at the effective release height, it is reasonable to assune that fumigation has occurred or is occurring. The diffusion computations made for the last time period should be redone using a fumigation model instead of an elevated plume model, because effluent released in the period between the observations is involved in the fumigation. The wind direction at 
plume height during fumigation precursor conditions determines the receptors that are exposed to high concentrations when fumigation occurs. Diffusion computations for the period for which the current observation is representative should be made using the normal model for diffusion within the turbulent boundary layer, because during this period effluents will not be released into the stable upper layer. After the diffusion computations are completed, the fumigation potential flag is set to off, and the procedure returns to the point at which meteorological data are input. If the fumigation $\mathrm{flag}$ is of $f$ on the basis of the previous hour's meteorological observation, diffusion computations can be made using the boundary layer diffusion model, and the flag can be reset as appropriate on the basis of the current observations.

\section{EPISODE DURATION}

The time history of ground-level concentration of an effluent during a fumigation episode was shown in Figure 1. The duration of the episode is the period between the onset of the rapid downward mixing of the effluent and the time when the ground-level concentration decreases to a value that is associated with diffusion entirely within the boundary layer. It is a function of the wind speed at the plume height and distance. The duration decreases with increasing wind speed and increases with increasing distance. The variation of duration with distance and wind speed can be neglected if a sufficiently long duration is assumed so that the time-integrated concentrations at distant receptors are not underestimated. The 30 minute duration assumed in Regulatory Guide 1.145 should be conservative for use in routine evaluations. In emergency response situations, the duration of the episode should be estimated for important receptors using the observed wind speed and the distance to each receptor, i.e.,

$$
t_{r}=x_{r} / U
$$

where $t_{r}$ and $x_{r}$ are the episode duration for and distance to receptor $r$, respectively.

Assuming that the thickness of the mixing layer increases only up to the effective release height of the plume, the changes in ground-level concentration during the episode are caused only by changes in the diffusion coefficients. The increase in concentration in the initial portion of the episode is caused by an increase in the vertical diffusion coefficient. The decrease in concentration after the plume become uniformly mixed in the vertical results from increase in the horizontal diffusion coefficient.

Figure 4 shows the changes in the diffusion coefficients' magnitudes at two distances downwind as a function of time for this scenario. Prior to the onset of fumigation, the diffusion coefficients are assumed to have values associated with stability class $F$, and following the onset they are assumed to increase to values associated with stability class B. The diffusion coefficient parameterizations used in the example are those used in XOQDOQ (Sagendorf, Goll and Sandusky 1982), PAVAN (Bander 1982), and other NRC diffusion models that are attributed to Eimutis and Konicek (1972). An effective release height of $100 \mathrm{~m}$ and a wind speed of $2 \mathrm{~m} / \mathrm{s}$ have been assumed. 


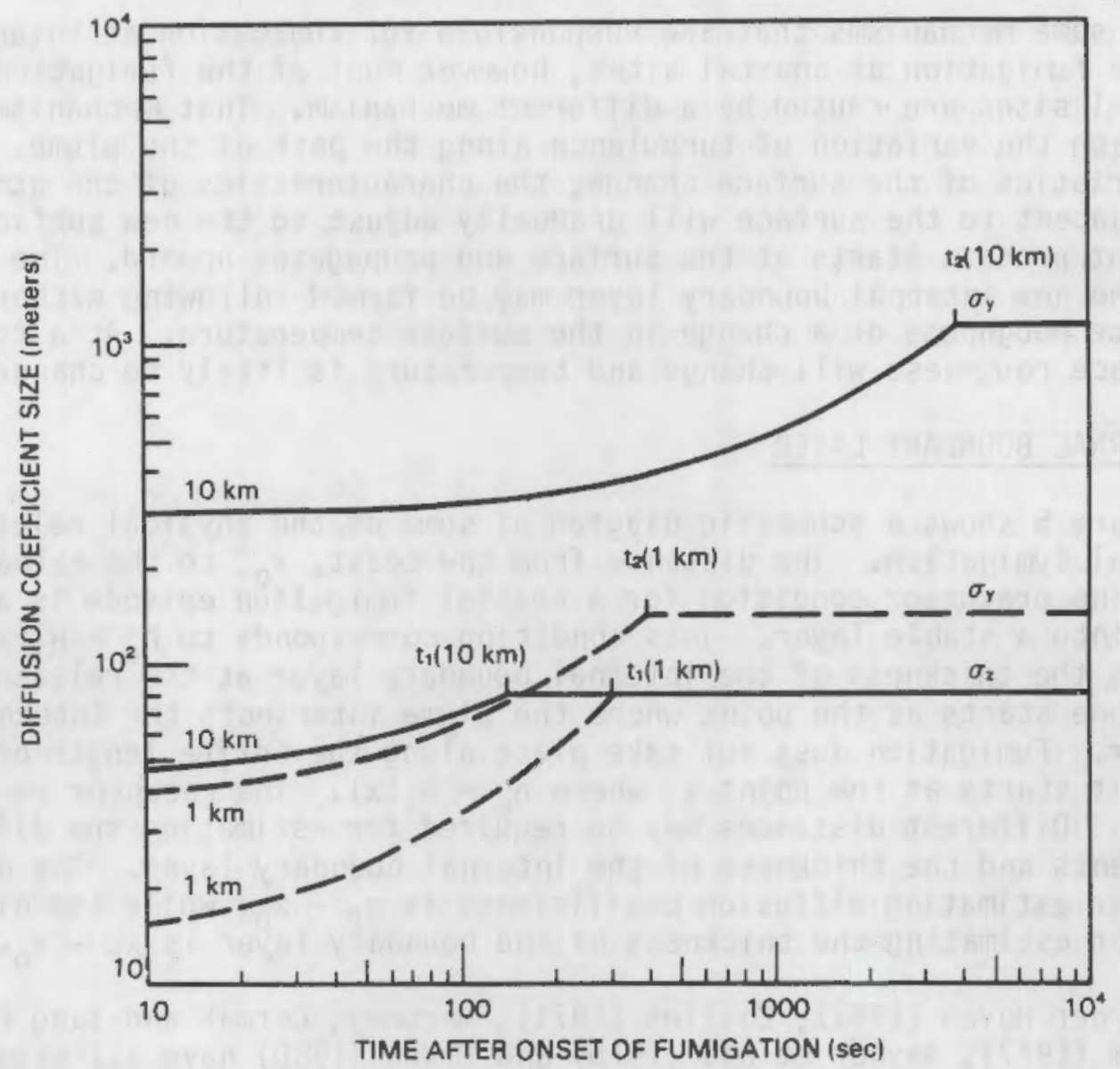

FIGURE 4. Growth of Diffusion Coefficients at One and Ten Kilometers During the Course of an Inland Fumigation Episode.

At one kilometer, it takes about 300 seconds for sigma $z$ to increase to 80 meters $(0.8 \mathrm{H})$. This is indicated in Figure 4 by the point marked $t_{1}(1 \mathrm{~km})$. Shortly thereafter at 400 seconds, sigma $y$ reaches its steady-state B stability value of 140 meters. When this occurs, the fumigation episode at one kilometer has come to an end. The duration of the episode at one kilometer is $400 \mathrm{sec}-$ onds, or less than seven minutes.

At ten kilometers, sigma $z$ reaches its final value in about 150 seconds (marked $\left.t_{1}(10 \mathrm{~km})\right)$. The more rapid accomodation of sigma $z$ to the change in turbulence conditions at ten kilometers is due to the growth in sigma $z$ between 1 and $10 \mathrm{~km}$. During the $150 \mathrm{~seconds}$ that are required for sigma $z$ to reach its equilibrium value, there is little change in sigma $y$. Ultimately, it takes about 4000 seconds for the episode at ten kilometers to come to an end (marked $\left.t_{2}(10 \mathrm{~km})\right)$. 


\section{FUMIGATION AT COASTAL SITES}

The same mechanisms that are responsible for fumigation at inland sites may cause fumigation at coastal sites, however most of the fumigation episodes at coastal sites are caused by a different mechanism. That mechanism is associated with the variation of turbulence along the path of the plume. When the characteristics of the surface change, the characteristics of the atmospheric layer adjacent to the surface will gradually adjust to the new surface. The adjustment process starts at the surface and propagates upward. The layer having the new internal boundary layer may be formed following either a change in surface roughness or a change in the surface temperature. At a coastline the surface roughness will change and temperature is likely to change.

THE INTERNAL BOUNDARY LAYER

Figure 5 shows a schematic diagram of some of the physical relationships in coastal fumigation. The distance from the coast, $x_{0}$, to the release point is $x_{p}$. The precursor condition for a coastal fumigation episode is an elevated release into a stable layer. This condition corresponds to $h_{e}>H_{j}\left(x_{p}\right)$ where $H_{j}\left(x_{p}\right)$ is the thickness of the internal boundary layer at the release point. The episode starts at the point where the plume intersects the internal boundary layer. Fumigation does not take place along the entire length of the plume. It starts at the point $x_{j}$ where $h_{e}=H_{j}(x)$. The receptor is located at point $x_{r}$. Different distances may be required for estimating the diffusion coefficients and the thickness of the internal boundary layer. The distance needed for estimating diffusion coefficients is $x_{r}-x_{p}$, while the distance needed for estimating the thickness of the boundary layer is $x_{r}-x_{0}$.

Van der Hoven (1967), Collins (1971), Meroney, Cermak and Yang (1975), Venkatram (1977), Raynor et al. (1975) and Misra (1980) have all studied the onshore internal boundary layer that forms downwind of a coastline. In general, the thickness of the boundary layer increases in proportion to the

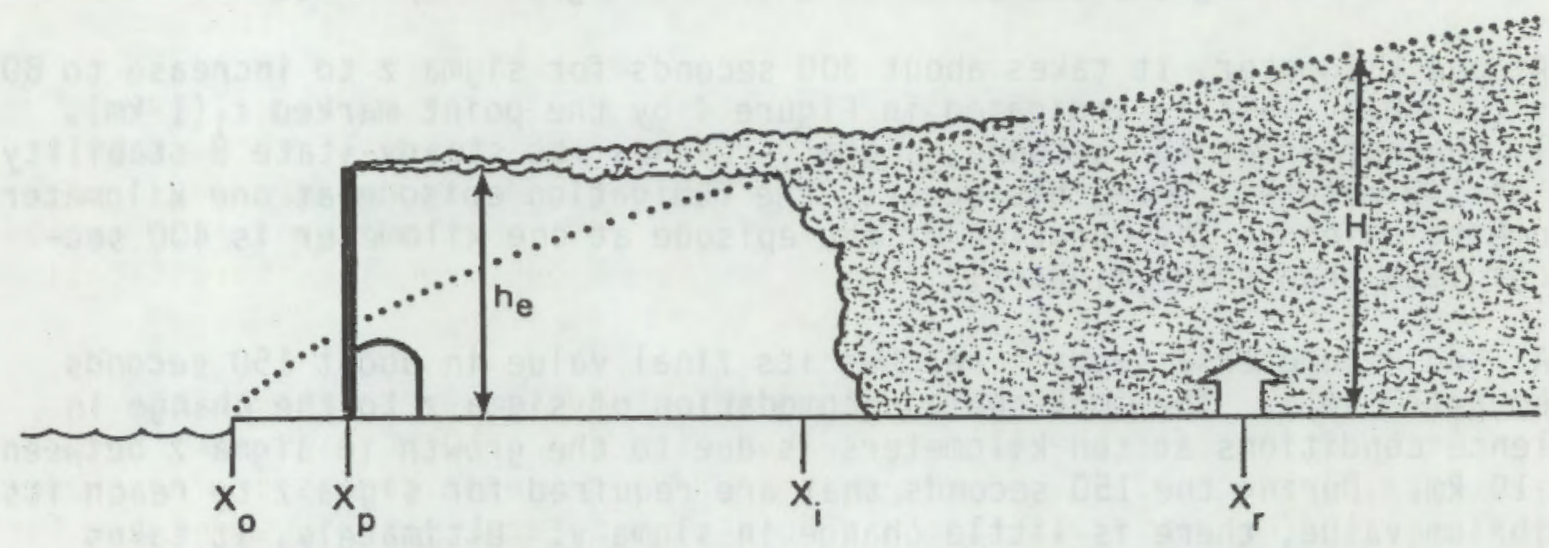

FIGURE 5. Schematic Representation of a Coastal Fumigation Episode, Showing Important Distances 
square root of the distance from the coast. Other factors that affect the growth of the internal boundary layer include: the temperature difference between the water and $l$ and, the wind speed and friction velocity within the internal boundary layer, and the potential temperature lapse over the water.

The model of Raynor, et al (1975) provides a starting point for the development of an operationl method for estimating the thickness of the internal boundary layer. That model is:

$$
H_{i}(x)=\frac{U_{\star}}{U}\left[\frac{x\left|\theta_{L}-\theta_{S}\right|}{|\partial T / \partial z|}\right]^{1 / 2}
$$

where $\theta_{1}$ and $\theta_{S}$ are the potential temperatures of the air at the surface over the 1 and and water, respectively, and $\partial T / \partial z$ is the temperature gradient in the air over the water. The remaining terms remain as previously defined. Other models could have been selected, but this model was selected because it explicitly treats the factors that are most important in internal boundary growth.

The model in (11) requires information that is not readily available at power plants. However, it can be simplified, as necessary, by assuming reasonable values for the terms for which data are not available. Van Dop, Steenkist amd Nieuwstadt (1979) used a simplified model

$$
H_{j}(x)=a x^{1 / 2}
$$

in which all of the physics was contained in the constant a.

Counihan (1975) gives a range of 0.02 to 0.03 for $U_{\star} / U$ for smooth surfaces in neutral atmospheric conditions. Using a value of 0.025 for this ratio and assuming an overwater 1 apse rate, the rate of growth of the internal boundary layer becomes a function only of the land-water termperature difference and the distance. In general, water temperatures change slowly compared to land temperatures and don't vary much from seasonal averages on a year-to-year basis. As a result, the water temperature may be replaced by a climatological average that is a function of time of year if better information is not available. With this substitution, the model only requires specification of the land temperature on a real time basis.

Figure 6 shows the growth of the internal boundary layer with three different assumptions for the overwater stability and a $10^{\circ} \mathrm{C}$ land-water temperature difference. A $10^{\circ} \mathrm{C}$ temperature difference is realistic for summer afternoons along the United States East Coast. The lapse rates assumed are for $\mathrm{G}, \mathrm{F}$ and $\mathrm{E}$ over-water stabilities, $0.06{ }^{\circ} \mathrm{C} / \mathrm{m}, 0.03{ }^{\circ} \mathrm{C} / \mathrm{m}$ and $0.01{ }^{\circ} \mathrm{C} / \mathrm{m}$. These values are within the ranges given in Regulatory Guide 1.23. - The value of the constant a assumed by Van Dop, Steenkist and Ni euwstadt (1979) was $4 \mathrm{~m}^{\mathrm{I} / 2}$. This value gives more rapid growth of the internal boundary layer than shown in Figure 6 . 


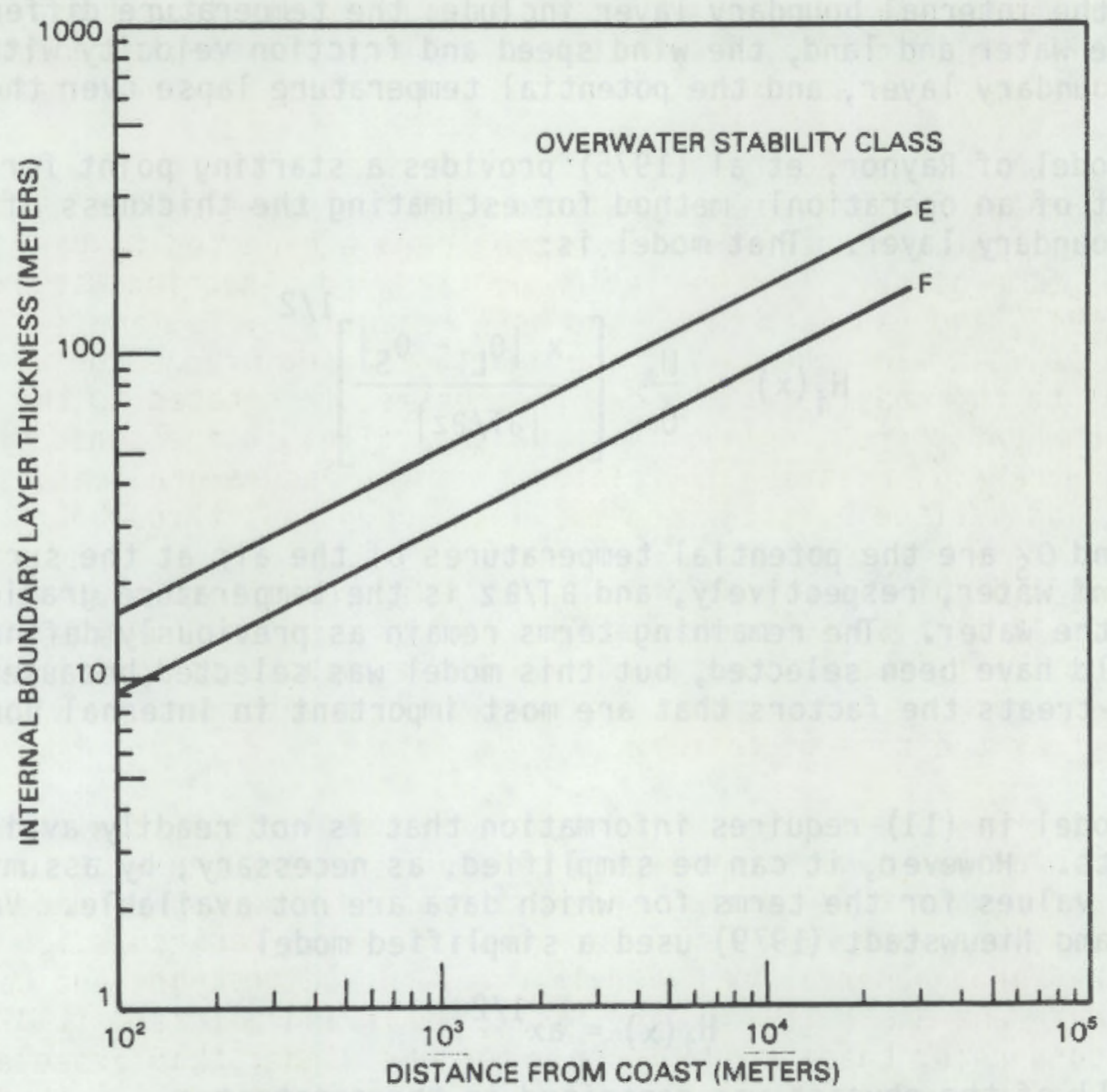

FIGURE 6. Typical Internal Boundary Layer Thickness as a Function of Distance from a Coastline Assuming "E" and "F" Over-Water Stability

Two important conclusions can be drawn from Figure 6 . The first is that coastal fumigation may occur well inland from a power plant located at a coast. The other conclusion is that a power plant located well inland from a coast could still have a release above the internal boundary layer so that the plume would be subject to coastal-type fumigation. These conclusions are supported by the observations of Portelli (1982) who found coastal fumigation zones that were 7 to $20 \mathrm{~km}$ inland.

\section{DURATION}

The inland-type of fumigation is brought about by a temporal change in the layered structure of the atmosphere. The change destroys the necessary precursor conditions for a fumigation episode. As a result, the maximum duration of an episode is 1 imited to the time required for the plume to transit from the source to the receptor. Unlike inland fumigation, coastal fumigation is brought about by a spatial change in the layered structure. Fumigation can continue as long as the precursor conditions are maintained. Extended periods 
of fumigation occur frequently along the shores of the Great Lakes (e. 9 . Lyons and Cole 1973, Keen and Lyons 1978, Portelli 1982). Portelli (1982) observed coastal funigation episodes extending to 8 hours in duration during a two-week period. This should not be interpreted to mean that a single receptor will necessarily experience abnormally high concentrations for the duration of the episode.

When coastal funigation is asociated with onshore flow during a sea or lake breeze circulation, the wind direction can be expected to vary as a function of time of day. The variation of the wind direction was explained by Haurwitz (1947) and has been discussed more recently by Ne umann (1977) and Burk and Staley (1979). In general, at the onset of a sea breeze the wind direction is parallel to the coast. As the day progresses, it rotates to the right (in the Northern Hemisphere), until it is again parallel to the coast at about sunset. The rate of rotation is related to the pressure gradient, surface roughness, and surface heating, and may not be constant throughout the day.

The rotation of the wind direction has a second effect that should be considered. If a release occurs at about the time of the onset of the sea breeze circulation, the effluent may be brought onshore as the circulation develops resulting in a funigation episode at a receptor that was not downind of the plant at the time of release.

While the primary fumigation concern at coastal sites is with onshore flow, fumigation can also occur during offshore flow if the water is wamer than the 1 and. When this occurs, the next onshore flow may produce higher concentrations than otherwise expected at the coast. Recirculation of effluents has been observed by several groups including Lyons and Cole (1976), Lamb, Lorenzen and Shair (1978), and McRae, Shair and Seinfeld (1982). Coasta 1 concentrations under these conditins may also be higher than expected because the growth of the internal boundary layer over water is not expected to be as rapid as the growth over land. However, this expectation has not been confimed by experimental data.

\section{ESTIMATING COASTAL FUMIGATION CONCENTRATIONS}

Models for estimating concentrations during coastal fumigation episodes have been developed by many groups, including: Lyons and Cole (1973), Venkatram (1977), van Dop, Steenkist and Nieuwstadt (1979), and Misra (1980). In general they require stability data that may not be readily available. Raynor, Michael and SethuRaman (1980) discuss the problems associated with estimating stability during onshore flow. Specifically, temperature differences do not provide a reliable indication of stability if the sensors are not in the same atmospheric layer. Figure 6 indicates that temperature difference measurements may have to be made well inland, if they are to be useful.

Assuming that the problem of estimating stability during onshore flow has been resolved adequately, the following method of treating coastal fumigation is offered as a compromise between realism and simplicity. Assume that the possibility for coastal fumigtion exists whenever there is onshore flow and that Class E stability exists over water. Determine if the precursor condi- 
tions are met by estimating the effective release height for the existing wind speed at release height and E stability, and the height of the internal boundary layer at the release point using (11) or (12). The precursor conditions exist if $h_{e}$ exceeds $H_{j}\left(x_{p}\right)$.

If fumigation precursor conditions exist, the distances from coast and plant to the point at which fumigation starts must be estimated. The distance from the coast at which fumigation starts is computed first by setting $H_{j}\left(x_{j}\right)=$ $h_{e}$ and solving for $x_{i}$. The distance from the plant to the point of fumigation is determined from $x_{i}$ by subtracting $x_{p}$. The distance from the power plant to the receptor $\left(x_{r}-x_{p}\right)$ is then computed. If this distance is less than the distance from the power plant to the point of fumigation, the concentration at the receptor should be est imated using the normal elevated release diffusion equation with coefficients appropriate to $E$ stability. If the comparison of distances indicates that the receptor is in the fumigation zone, diffusion computations should be made using a model that treats both the diffusion between the plant and the point of fumigation and that following the onset of fumigation. This can be accomplished relatively easily within the framework of the Gaussian continous plume model.

To estimate the concentration at the receptor, the diffusion coefficients, sigma $y$ and sigma $z$, are computed for the fumigation distance using the upwind stability. Distances to virtual point sources are then computed from the coefficients assuming the stability within the internal boundary layer. Finally, concentrations within the internal boundary layer are computed using the distances between the receptor and the virtual point source to estimate the diffusion coefficients. When sigma $z$ grows to $0.8 \mathrm{H}_{j}(x)$ the form of the model used should be changed to that with a uniform vertical concentration profile. The change in model forms could be made at the fumigation point, thereby el iminating the need to compute a virtual distance for sigma $z$.

Again it should be noted that there is more than one distance involved in these computations. The thickness of the internal boundary layer must be computed using the distance from the coast, while the diffusion coefficients must be computed using the distances from the actual or virtual release points.

For offshore flow, fumigation should be anticipated ony when the water temperature exceeds the land temperature. In this case, the problems associated with determining stability from tower measurements should be minimal, and the computational approach outlined above can be followed. The estimates of the thickness of the internal boundary layer for offshore flow may be somewhat low because the transition is from a relatively rough to a smooth surface. However, if the temperature difference is large, the underestimate should be minimal because the effects of instability due to the warm surface will domi nate. 
The methods of treating fumigation outlined in Regulatory Guide 1.145 (USNRC 1983) provide a reasonable approach to estimation of relative concentrations for use in evaluation of the consequences of potential accidents at nuclear power plants. This section discusses a number of minor modifications to the current Regulatory Guide criteria that could improve the realism in the criteria.

\section{REGULATORY POSITION 1.}

The diffusion models represented by Equations (4) and (5) in Regulatory Guide 1.145 are appropriate for estimating ground-level relative concentrations during normal and fumigation diffusion conditions, respectively. They can be derived directly from (1) by truncating the summation and making appropriate assumptions. However, Equation (5) of the Regulatory Guide could be clarified if the effective stack height were replaced by the mixing layer thickness. The basic assumption in derivation of the fumigation model is that material is uniformly mixed throughout the mixing layer. The onset of fumigation corresponds with an increase in mixing layer thickness to the effective stack neight. After the onset of fumigation the effective stack height is not longer relevant.

The procedure discussed in the last paragraph of Section 1.3 is misleading and may not be conservative in all instances. The problem with the discussion is caused by the use of the effective release height in the Regulatory Guide Equation 5 in place of the mixing layer thickness. Although equality of the two values is assumed at the onset of fumigation, the two parameters do not represent the same physical entities. It may be reasonable to allow the plume to impact terrain by decreasing the effective release height along the plume path, but it is not reasonable to allow the mixing layer thickness to go to zero.

Similarly, it is not reasonable to assume that at some point along the path of the plume the mixing layer thickness makes a step increase to a value so large that the vertical growth of the plume is no longer restricted by the top of the mixing layer. This is the assumption that must be made when reverting to the use of Equation 4 of the Regulatory Guide during fumigation conditions. It would be more appropriate to define an effective mixing layer thickness along the lines of the definition of the effective release height in Regulatory Guide 1.111, with the condition that it have a minimum value greater than zero. The minimum value could be made a function of the wind speed. Defining a mixing layer thickness as a function of distance is appropriate for coastal nuclear power plant sites, as well as for sites in valleys and near hills.

\section{REGULATORY POSITION 2.}

In Regulatory Position 2, the NRC distinguishes between the inland and coastal sites entirely on the basis of distance from the shoreline. The distance selected as the boundary is $3.2 \mathrm{~km}$. This distance may not be adequate. 
A coastal-type fumigation situation is conceivable for power plants located somewhat farther inland. A more realistic approach to differentiating between inland and coastal sites might include consideration of effective stack height under stable atmospheric conditions as well as the minimum distance to the coastline.

\section{Inland Sites}

At inland sites, the precursor conditions for fumigation require that the effective stack height be greater than the thickness of turbulent boundary layer. Simple models are available to estimate the effective release height and the mixing layer thickness.

Inland fumigation is a transient phenomenon. This transient nature is recognized in the Regulatory Position. However, the duration of fumigation episodes depends on the distance between the source and receptor. Assuming a one-half hour fumigation episode duration, as is done in the current Regulatory Position, is generally conservative near the source. It may not be conservative as the distance from the source increases. An alternative position, which would be conservative at all distances, would be to assume that the duration of fumigation episodes is one-half hour or the time required to reach the receptor at the release height wind speed, whichever is longer.

The precursor conditions for inland fumigation imply moderately or extremely stable conditions in the layer of the atmosphere into which the plume is released. Following the onset of fumigation, the plume will be in a neutral or unstable layer. It is conservative to use diffusion coefficients for the stable atmospheric conditions with the fumigation model during the course of the fumigation episode. After the fumigation episode, the use of stable diffusion coefficients may be excessively conservative. Use of neutral atmospheric diffusion coefficients for the period following the fumigation episode is more appropriate and should still provide conservative estimates of timeintegrated concentrations.

Coastal Sites

Onsite definition of precursor conditions for coastal fumigation is more difficult than it is for inland fumigation. As a result, precursor conditions for coastal fumigation should be assumed to exist at all times during onshore flow, unless the data are available to permit reliable estimation of the internal boundary height and the effective stack height at the source is known to be less than the internal boundary layer thickness. During offshore flow, fumigation precursor conditions should be assumed to exist when the water temperature is greater than the land temperature. $\mathrm{Cl}$ imatological average temperatures may be adequate for making this determination for potential accidents.

Coastal fumigation is caused by a spatial transition in the structure of the atmosphere. As a result, the duration of a coastal fumigation episode is not well defined. Available data indicate that fumigation over land can continue essentially as long as there is onshore flow. The Regulatory Position that coastal fumigation be assumed to occur for two hours at the exclusion area 
boundaries and four hours at the low population zone boundaries of power plants may not be conservative for coastal sites, even when applied to specific sectors. However, rotation of the wind direction with time during onshore flow reduces the likelihood that fumigation will continue in a single sector for more than two hours.

\section{APPLICATION TO EMERGENCY RESPONSE}

Conceptually, the diffusion models described in Section 1.3 .2 of Regulatory Guide 1.145 are appropriate for use in estimating time-integrated concentrations near a nuclear power plant in the event of an emergency. However, if they are to be used under these conditions, the mixing layer thickness in Equation 5 should be defined independent of the effective release height. If the power plant site is near a coast or in a location where terrain impaction is possible, it should be given as a function of distance and direction from the site. If sufficient data are available, the mixing layer thickness may also be related to environmental variables such as wind speed, atmospheric stability and water-land temperature differences.

When applying the models in an emergency response situation, the assumptions in Regulatory Guide 1.145 with respect to the existence of fumigation conditions may be too conservative. The procedure outlined earlier in this report provides a method for evaluating fumigation potential on a continuous basis. Following the procedure should result in more realistic time-integrated concentration estimates than would result from making the assumptions contained in the Regulatory Guide. 


\section{REFERENCES}

Bander, T. J. 1982. PAVAN: An Atmospheric Dispersion Program for Evaluating Design Basis Accidental Releases of Radioactive Materials from Nuclear Power Stations. NUREG/CR-2858 (PNL-4413), U.S. Nuclear Regulatory Commission. Washington, D.C.

Benkley, C. W. and L. L. Schulman. 1979. "Estimating Hourly Mixing Depths from Historical Meteorological Data." J. Appl. Meteor., 35:1231-1239.

Burk, S. D., and D. 0. Staley. 1979. "Comments on the Rotation Rate of the Direction of Sea and Land Breezes." J. Atmos. Sci., 36:369-371.

Caughey, S. J., J. C. Wyngaard, and J. C. Kaimal. 1979. "Turbulence in the Evolving Stable Boundary Layer." J.Atmos. Sci., 36:1014-1052.

Clarke, R. H., A. J. Dyer, R. R. Brooke, D. G. Reid and A. J. Troup. 1971. "The Wangara Experiment, Boundary Layer Data." Paper No. 19, Division of Meteorological Physics, CSIRD, Australia.

Collins, G. F. 1971. "Predicting 'Sea-Breeze Fumigation' from Tall Stacks at Coastal Locations." Nuclear Safety, 12:110-114.

Counihan, J. 1975. "Adiabatic Atmospheric Boundary Layers: a Review of Data from the Period 1880-1972." Atmos. Environment. 9:871-905.

Csanady, G. T. 1973. Turbulent Diffusion in the Environment. D. Reidel, Boston, 295p.

Eimutis, E. C. and M. G. Konicek. 1972. "Derivations of Continous Functions for the Lateral and Vertical Atmospheric Dispersion Coefficients." Atmos. Environ., 6:859-863.

Hanna, S. R. 1969. "The Thickness of the Planetary Boundary Layer." Atmos. Environ., 3:519-536.

Hanna. S. R., G. A. Briggs, and R. P. Hosker. 1982. Handbook on Atmospheric Diffusion. D0E/TIC-11223, U.S. Department of Energy, 108p.

Haugen, D. A. (ed). 1973. "Workshop on Micrometeorology." American Meteorological Society, Boston.

Haurwitz, B. 1947. "Comments on the Sea Breeze Circulation." J. Meteor., $4: 1-8$.

Hewson, W. E. and G. C. Gi11. 1944. Meteorological Investigations in Columbia River Valley near Trail, B.C. U.S. Bur. of Mines BuTl. 453, Washington, DC.

Kaima1, J. C. 1973. "Turbulence Spectra, Length Scales and Structure Parameters in the Stable Boundary Layer." Boundary-Layer Meteor., 4:289-309. 
Kaimal, J. C., J. C. Wyngaard, D. A. Haugen, O. R. Cote, Y. Is umi, S. J. Caughey and C. J. Readings. 1976. "Turbulence Structure in the Convective Boundary Layer." J. Atmos. Sci., 33:2152-2169.

Keen, C. S. and W. A. Lyons. 1978. "Lake/Land Breeze Circulation on the Western Shore of Lake Michigan." J. Appl. Meteor., 17:1843-1855.

Lettau, H. H. and B. Davidson (eds). 1957. Exploring the Atmosphere's First Mile. Vol. 2. Pergamon Press.

Lyons, W. A. and H. S. Cole. 1973. "Fumigation and Plume Trapping on the Western Shore of Lake Michigan During Stable Onshore Flow." J. Appl. Meteor., 12:494-510.

Lyons, W. A. and H. S. Cole. 1976. "Photochemical 0xidant Transport: Mesoscale Lake Breeze and Synoptic-Scale Aspects." J. Appl. Meteor., 15:733-743.

McRae, G. J., F. H. Shair, and J. H. Seinfeld. 1982. "Convective Downmixing of Plumes in a Coastal Environment." J. Appl. Meteor., 20:1312-1324.

Mahrt, L., J. C. Andre and R. C. Heald. 1982. "On the Depth of the Nocturnal Boundary Layer." J. Appl. Meteor., 21:90-92.

Mahrt, L. 1981. "Modelling the Depth of the Stable Boundary Layer." Boundary-Layer Meteor., 21:3-19.

Melgarejo, J. W. and J. W. Deardorff. 1974. "Stability Functions for the Boundry Layer Resistance Laws Based Upon Observed Boundary Layer Heights." J. Atmos. Sci., 31:1324-1333.

Meroney, R. N., J. E. Cermak and B. T. Yang. 1975. "Modeling of Atmospheric Transport and Fumigation at Shorel ine Sites." Boundary-Layer Meteor., 9:69-90.

Misra, P. K. 1980. "Verification of a Shore-Line Dispersion Model for Continuous Fumigation." Boundary-Layer Meteor., 19:501-507.

Neumann, J. 1977. "On the Rotation Rate of the Direction of Sea and Land Breezes." J.Atmos. Sci., 34:1913-1917.

Pasquill, F. 1974. Atmospheric Diffusion (2nd ed.), Halstead Press, 429 p.

Portelli, R. B. 1982. "The Nanticoke Shoreline Diffusion Experiment, June 1978--I. Experimental Design and Program Overview." Atmos. Environ., $16: 413-421$.

Raynor, G. S., P. Michael, R. M. Brown and S. SethuRaman. 1975. "Studies of Atmospheric Diffusion from a Nearshore Oceanic Site." J. Appl. Meteor., 14:1080-1094. 
Raynor, G. S., P. Michael and S. SethuRaman. 1980. "Meteorological Measurement Methods and Diffusion Models for Use at Coastal Nuclear Reactor Sites." Nuclear Safety, 21:749- 765.

Readings, C. J., D. A. Haugen and J. C. Kaimal. 1974. "The 1973 Minnesota Atmospheric Boundary Layer Experiments." Weather, 29:309-312.

Sagendorf, J. F., J. T. Goll and W. F. Sandusky. 1982. X0QD0Q: Computer Program for the Meteorological Evaluation of Routine Effluent Releases at Nuclear Power Stations. NUREG/CR-2919 (PNL-4380), U.S. Nuclear Regulatory Commission, Washington, DC.

Sl ade, D. H., ed. 1968. Meteorology and Atomic Energy-1968. U. S. Atomic Energy Commission, TID-24190, Washington, DC.

Touma, J. S. 1977. "Dependence of the Wind Profile Power Law on Stability for Various Locations." J. Air Pollut. Control Assoc., 27:863-866.

Townsend, A. A. 1966. "Wind and the Formation of Inversions." Atmos. Environ., 1:173-175.

U.S. Nuclear Regulatory Commission. 1974. Onsite Meteorological Programs. Regulatory Guide 1.23 (formerly Safety Guide 23), Washington, DC.

U.S. Nuclear Regulatory Commission. 1983. Atmospheric Dispersion Models for Potential Accident Consequence Asses sments at Nuclear Power Plants. Regulatory Guide 1.145, Washington, DC.

Van der Hoven, I. 1967. "Atmospheric Transport and Diffusion at Coastal Sites." Nuclear Safety, 8:490-499.

van Dop, H., R. Steenkist and F. T. M. Nieuwstadt. 1979. "Revised Estimates for Continous Shoreline Fumigation." J. Appl. Meteor., 18:133-137.

Venkatram, A. 1977. "A Model of Internal Boundary Layer Development and Fumigation." Boundary-Layer Meteor., 11:419-437.

Wetzel, P. J. 1982. "Toward Parameterization of the Stable Boundary Layer." J. Appl. Meteor., 21:7-13.

Yu, T. 1978. "Determining Height of the Nocturnal Boundary Layer." J. Appl. Meteor., 17:28-35. 
No. of

Copies

OFFSITE

U.S. Nuclear Regulatory Commission

Division of Technical Information and Document Control

$4 \mathrm{Mr}$. J. Fairobent

Division of System Integration Office of Nuclear Reactor Regulation

U.S. Nuclear Regulatory Commission Washington, DC 20555
No. of

Copies

ONSITE

50 Pacific Northwest Laboratory

K. J. Allwine

G. F. Athey

D. W. Dragnich

J. C. Doran

J. G. Droppo

D. W. Faletti

C. S. Glantz

R. K. Hadlock

C. G. Lindsey

M. A. Mclean

J. V. Ramsdell (31)

W. F. Sandusky

C. D. Whiteman

Publishing Coordination (2)

Technical Information (5) 



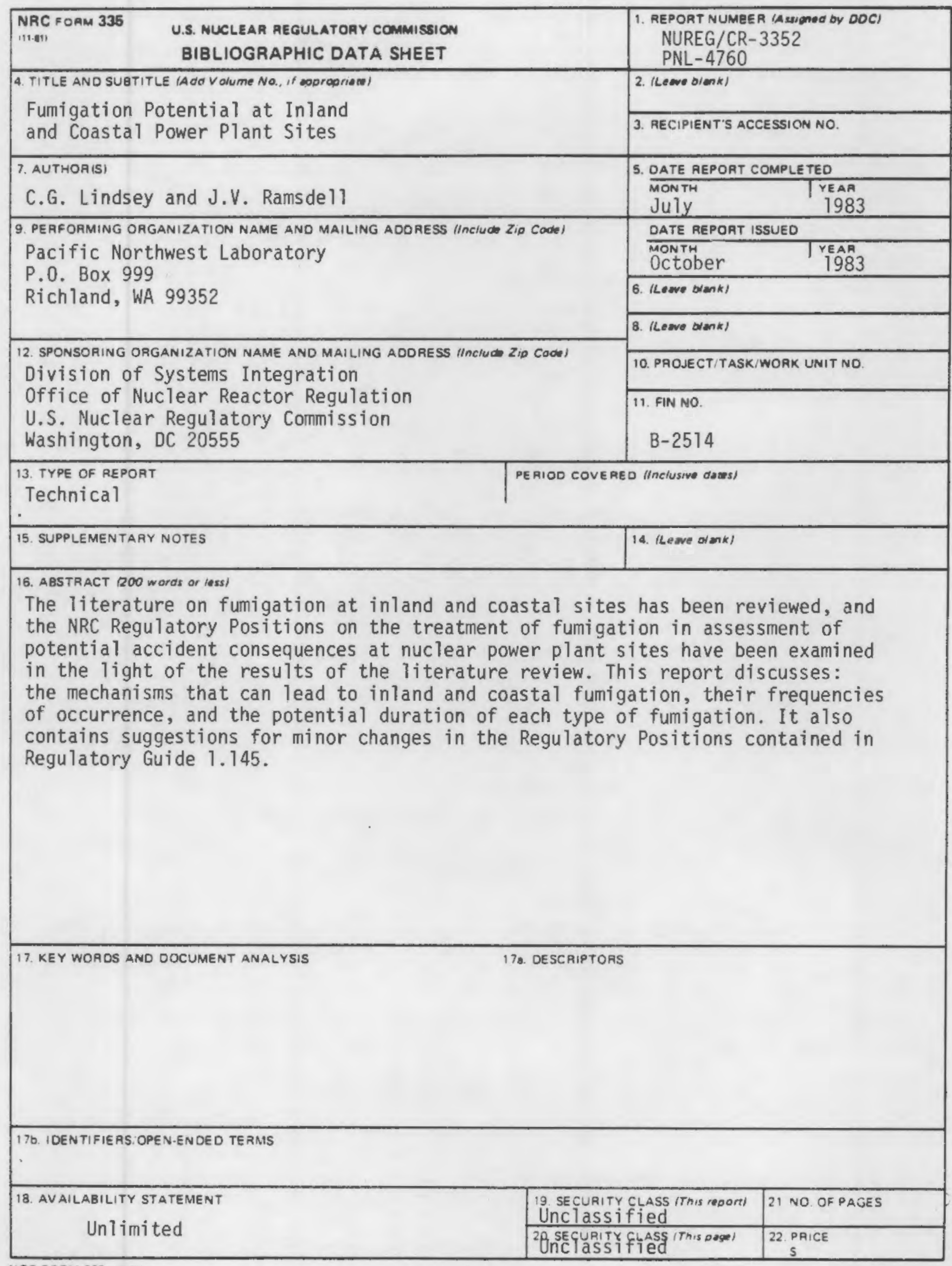


